Research Article

\title{
Multifunctional Silver Nanoparticles by Fruit Extract of Terminalia belarica and their Therapeutic Applications: A 3-in-I System
}

\author{
Sucharitha Kumaram Venkata ${ }^{1 \dagger}$, Susmila Aparna Gaddam ${ }^{2 \dagger} \simeq$, Venkata Subbaiah Kotakadi ${ }^{3 \dagger}$, Divi \\ Venkata Ramana Sai Gopal ${ }^{2,3}$ \\ ${ }^{1}$ Department of Home Science, Sri Venkateswara University Tirupati-517502, Andhra Pradesh, India. \\ ${ }^{2}$ Department of Virology, Sri Venkateswara University Tirupati-517502, Andhra Pradesh, India. \\ ${ }^{3}$ DDST-PURSE Centre, Sri Venkateswara University Tirupati-517502, Andhra Pradesh, India. \\ ${ }^{\dagger}$ Authors contributed equally to the work. \\ Corresponding authors. E-mail: suchivenkata@gmail.com; susmilaaparna@gmail.com; kotakadi72@gmail.com
}

Received: Apr. 28, 2018; Accepted: Aug. 3, 2018; Published: Sep. 11, 2018.

Citation: Sucharitha Kumaram Venkata, Susmila Aparna Gaddam, Venkata Subbaiah Kotakadi, and Divi Venkata Ramana Sai Gopal, Multifunctional Silver Nanoparticles by Fruit Extract of Terminalia belarica and their Therapeutic Applications: A 3-in-1 System. Nano Biomed. Eng., 2018, 10(3): 279294.

DOI: $10.5101 /$ nbe.v10i3.p279-294.

\begin{abstract}
The use of nanoparticles in treating dreadful diseases like cancer is the emerging field of research in cancer therapy. In the present investigation, the green biosynthesis of silver nanoparticles (AgNPs) with aqueous fruit extract of Terminalia belarica has been carried out, and ultraviolet-visible spectroscopy (UV-Vis) analysis was done which revealed an intense surface plasmon resonance (SPR) band at $430 \mathrm{~nm}$, thus confirming the formation of $T b$-AgNPs. The AgNPs were further characterized by Fourier transform-infrared spectroscopy (FTIR), showing the reduction of silver nitrate into Tb-AgNPs by the reduction of different functional groups such as hydroxyl, phenols, stretch of aldehydes, alkenes and aromatics. Transmission electron microscopy (TEM) and diffraction light scattering (DLS) study showed that the nanoparticles were round in shape with an average size of $46.5 \mathrm{~nm}$. The atomic force microscopy (AFM) analysis also revealed similar results to facilitate that the AgNPs were round in shape, and the size was calculated by Z-coloration method. Furthermore, the X-ray diffraction (XRD) data confirmed that $T b$-AgNPs were crystalline with face centered cubic (fcc) structure and were very stable with $-29.1 \mathrm{mV}$ Zeta potential. $\mathrm{Tb}$-AgNPs showed efficient free radical scavenging activity against 2,2-diphenyl-1-picrylhydrazyl, hydrogen peroxide and nitric oxide. The 2,2-diphenyl-1-picrylhydrazyl (DPPH) method was the best among the three antioxidant methods with the half maximal inhibitory concentration $\left(\mathrm{IC}_{50}\right)$ value of $47.25 \pm 0.17$. Tb-AgNPs also showed superior and efficient antibacterial activity greater than the control antibiotic, and showed effective anti-proliferative and cytotoxic effect on human breast cancer cells with $\mathrm{IC}_{50}$ value of $73.18 \mu \mathrm{g} / \mathrm{mL}$. The biosynthesized $\mathrm{Tb}$-AgNPs with multifunctional properties could be employed as a source for the exploration of novel therapeutic antioxidant, antibacterial and anticancer agent.
\end{abstract}

Keywords: Green synthesis; Terminalia belarica; Spectral characterization; AFM Z coloration analysis; Antioxidant activity; Antimicrobial activity; Anticancer activity 


\section{Introduction}

The focus on traditional and modern nanomedicine leads to evolved green synthesis of silver nanoparticles (AgNPs) from different medicinal plant extracts. For the past two decades, understanding the properties of these nanoparticles has contributed to their applications in medicine. Synthesis of nanoparticles using physical methods such as photo chemical reduction, laser irradiation technique, aerosol technique, etc. [1-3], and chemical methods such as reduction methods using chemical reductants including $\mathrm{NaBH}_{4}, \mathrm{~N}_{2} \mathrm{H}_{4}$, $\mathrm{NH}_{2} \mathrm{OH}$, ethanol, etc. [4-8] has been carried out for years. Sometimes, these methods were expensive and hazardous. So, green chemistry methods were found to be a good alternative for biosynthesis of metallic AgNPs; they were nonhazardous, simple, inexpensive and environment friendly. Green silver nanoparticles gained their potential in antibacterial, antifungal, anticancer and biomedical applications [9-15]. The plant extracts have more potential in the synthesis of metal nanoparticles as they contain polyphenols, alkaloids, fatty acids, proteins, flavonoids which help reducing and capping agents. Silver nanoparticles have been used as an effective antimicrobial agents due to their ability to induce the production of reactive oxygen species (ROS) which lead to apoptosis of the microbial organisms [16-17]. Similarly, AgNPs have been reported to induce oxidative stress in mammalian cells and also induce toxicity in cancer cells by triggering reactive oxygen species (ROS) production which can lead to apoptosis of the cancer cells [1819]. It was reported that biosynthesized AgNPs from a natural plant extract had exhibited anticancer activity in lung cancer cells [20]. As of the above findings, it is evidently explicit that the green AgNPs synthesized from natural sources might be used as an anticancer agent. Hence, the present study was initiated to study the effect of AgNPs on antibiotic resistant bacteria and human breast adenocarcinoma cell line (MCF-7). This work aimed at synthesizing AgNPs from aqueous fruit extract of Terminalia belarica and to characterize $\mathrm{Tb}$ AgNPs by different advanced spectroscopic methods and to study their antioxidant, antibacterial and anticancer activities. Terminalia belarica belongs to the Combretaceae family, genes Terminalia species Terminalia belarica, called as vibhitaka in Sanskrit. The fruit of Terminalia belarica is used as a herb in the popular Indian traditional ayurvedic medicine, called as Triphala. In this study, aqueous extract of the fruit was used to synthesize Tb-AgNPs, Spectral characterization was carried out to study their antioxidant, antibacterial and anticancer activities in MCF-7 cell lines, which is clearly illustrated in Schematic 1

\section{Experimental}

\section{Preparation of Terminalia belerica fruit extract}

The Terminalia belerica fruit powder was provided by a famous Ayurveda College located near Srinivasa Mangapuram, Tirupati. The aqueous fruit powder extract was ready by mixing $3 \mathrm{~g}$ of finely ground fruit powder in a $500 \mathrm{~mL}$ Erlenmeyer flask, with $300 \mathrm{~mL}$ of Milli-Q water. The blend was heated at $70{ }^{\circ} \mathrm{C}$ for 10 min and filtered with germ-free filter cloth, followed by Whatmann Grade 1 filter paper. The filtrate solution
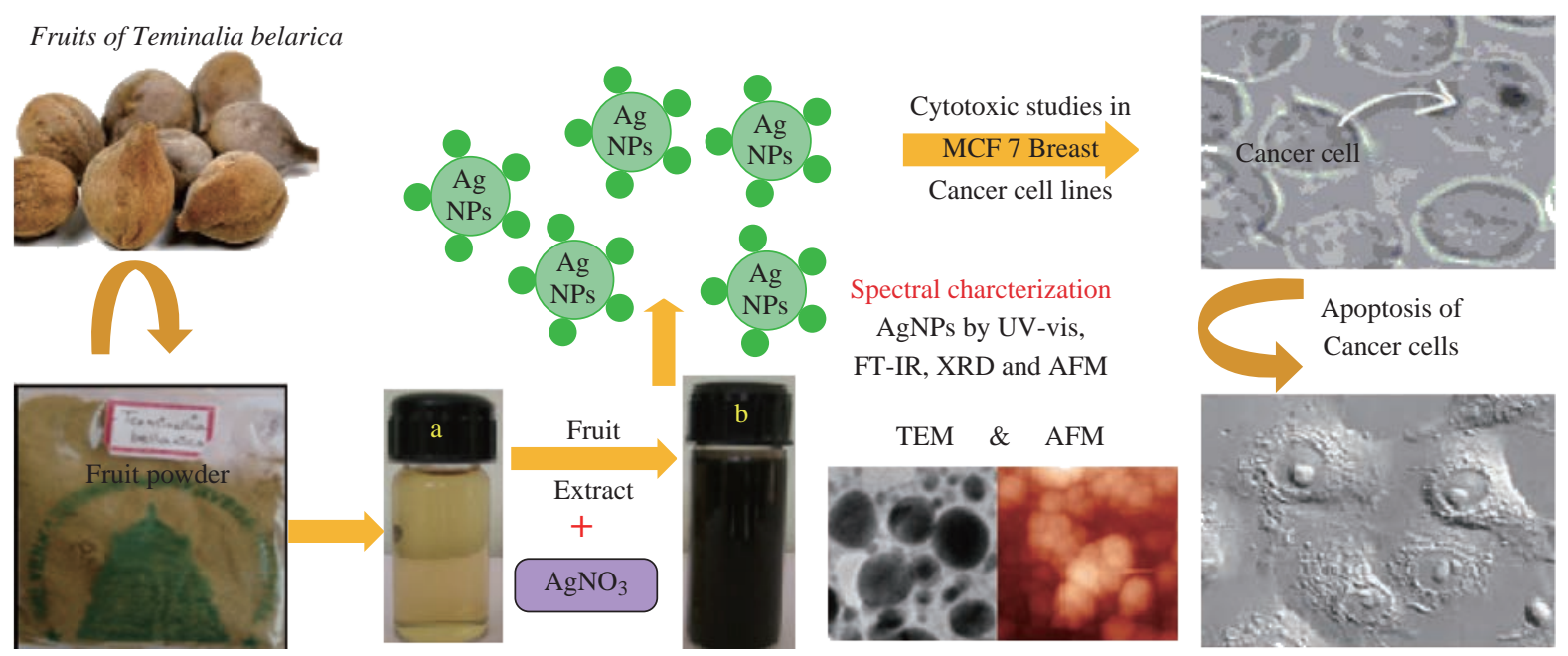

Schematic 1 Green synthesis of Tb-AgNPs and their characterization and applications. 
obtained (Fig. 1(a)) was a new source of aqueous extract for the biosynthesis of green AgNPs.

\section{Biosynthesis of AgNPs}

To the $10 \mathrm{~mL}$ diluted filtrate $(2 \mathrm{~mL}$ extract $+8 \mathrm{~mL}$ distilled water), $20 \mathrm{~mL}$ of $0.025 \mathrm{mM} \mathrm{AgNO}_{3}$ was added, and the sample was kept at room temperature, till the color of reaction solution altered from slight pale yellow to dark brown (Fig. 1(b)). This color change proved the presence of AgNPs. In the current process, the biosynthesis of silver nanoparticles was done by the aqueous fruit extract of Terminalia belerica without any external toxic chemicals.

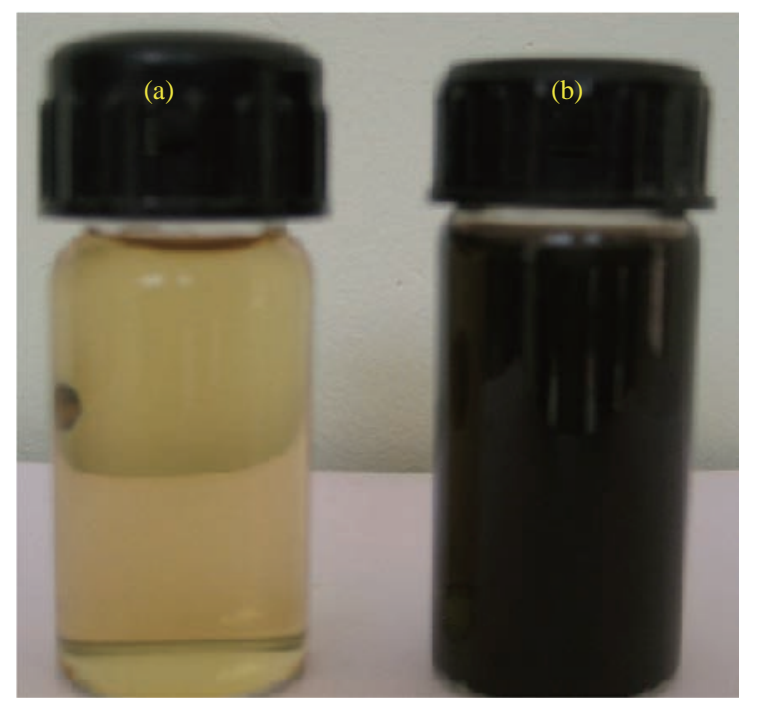

Fig. 1 (a) Fruit extract of Terminalia belarica; (b) Biosynthesized Tb-AgNPs by fruit extract of Terminalia belarica.

\section{Purification of AgNPs}

The solution containing AgNPs was centrifuged at $27,000 \mathrm{rpm}$ for $1 \mathrm{~h}$ to obtain the nanoparticle pellets. The AgNPs pellets were redispersed in sterile Milli-Q water to get rid of any biological molecules. The process of centrifugation and re-dispersion in ultrapure sterilized Milli-Q water was repeated three times to obtain better separation of entities from the metal nanoparticles and to get rid of unbound fruit extract residues. The biosynthesized and purified $T b$-AgNPs pellets were used for subsequent studies including Fourier-transform infrared spectroscopy (FTIR), $\mathrm{X}$-ray diffraction (XRD) and energy-dispersive X-ray spectroscopy (EDX), etc.

\section{Characterization of AgNPs}

The biosynthesized and bio-reduced pure aqueous
Tb-AgNPs solution with the fruit extract of Terminalia belerica was measured from time to time by sampling $1 \sim 3 \mu \mathrm{L}$ of $T b$-AgNPs solution. The optical density (OD) values of $T b$-AgNPs were recorded on Nanodrop 8000, UV-visible spectrometer (Thermo Scientific) in wavelength range of $220 \sim 770 \mathrm{~nm}$. The reading of the $T b$-AgNPs solution was done at room temperature on Nanodrop Spectrophotometer at the resolution of $1 \mathrm{~nm}$. After bioreduction and confirmation of the biosynthesis of $T b$-AgNPs, they were separated by centrifugation from the colloidal solution. Then, $T b$ AgNPs pellets were re-dispersed in sterile distilled water and purified by repetitive centrifugation for thrice. The final $\mathrm{Tb}$-AgNPs pellets obtained were dried up in hot air oven at $70{ }^{\circ} \mathrm{C}$ to get fresh, pure and finer particles of $T b$-AgNPs which were used for advance spectral characterization and bioactivity. The FTIR spectrum investigation was carried out to disclose the possible biomolecules of fruit extract of Terminalia belerica responsible for the biosynthesis and stabilization of $T b$-AgNPs. The analysis was done by using Alpha T model, FTIR Spectrophotometer (Bruker Company, Switzerland). EDX analysis was done by using scanning electron microscope $(200 \mathrm{kV})$ machine (Oxford Inca Penta FeTX3 EDS Instrument) with a line resolution of 2.32 in $\AA$ which was equipped with Carl Zeiss EVO MA 15 lens. The analysis of AgNPs was done with the help of a drop of coating on a small square bit of aluminum foil. Transmission electron microscopy (TEM) study was used to reveal the morphology, shape and size of AgNPs, by coating a drop of the purified aqueous AgNPs on a carboncoated copper grid, and the analysis was carried out by using FEI Tecnai F12 (Philips Optics Ltd, Holland) operated at $100 \mathrm{kV}$. Furthermore, selected area electron diffraction (SAED) pattern of AgNPs was also carried out using TEM. The same purified AgNPs solution was also used to detect surface charges, i.e. Zeta potential and also particle size in colloidal form by means of dynamic light scattering (DLS) technique by using Horiba Nanopartica analyzer, SZ-100. Morphological and topological studies of AgNPs were done by using atomic force microscopy (AFM). A tiny drop of purified aqueous $T b$-AgNPs solution was coated on a tiny square piece of aluminum sheet; it was assured that the sample was air dried completely without any moisture, prior to examination of the sample in AFM (Solver Next, NT-MDT, Russia). XRD study was conceded to prove the crystalline nature of the $T b$ AgNPs using Ultima IV X-ray powder diffractometer 
(Rigaku Ltd, Tokyo, Japan) by means of $\mathrm{Cu} \mathrm{K} \alpha$ radiation source.

\section{Free radical scavenging activity DPPH antioxidant activity}

The in-vitro antioxidant activity of the AgNPs was measured by 2,2'-diphenyl-1-picrylhydrazyl (DPPH) radical scavenging assay as described earlier [21]. 4 $\mathrm{mg}$ of DPPH was dissolved in $100 \mathrm{~mL}$ of methanol and stored at $20^{\circ} \mathrm{C}$. From the stock solution, $2 \mathrm{~mL}$ of the solution was added to $1 \mathrm{~mL}$ of methanol solution containing test samples of Terminalia belarica fruit extract and $T b$-AgNPs at different concentrations of 25 , 50, 75 and $100 \mu \mathrm{g} / \mathrm{mL}$. DPPH free radical scavenging activity (RSA) was measured at the absorbance of 517 $\mathrm{nm}$. The antioxidant activity was also expressed as $\mathrm{IC}_{50}$. Ascorbic acid was used as standard in the present study. The percentage of free radical scavenging activity was calculated by using Eq. (1) as follows:

$\operatorname{RSA}(\%)=[($ control absorbance - sample absorbance $) /$

control absorbance] $\times 100$.

\section{Hydrogen peroxide $\left(\mathrm{H}_{2} \mathrm{O}_{2}\right)$ scavenging activity}

$\mathrm{H}_{2} \mathrm{O}_{2}$ scavenging ability of the test compound was determined according to the literature method [22]. A solution of $\mathrm{H}_{2} \mathrm{O}_{2}$ (40 mM) was prepared in phosphate buffer ( $\mathrm{pH} 7.4) .25,50,75$ and $100 \mu \mathrm{g} /$ $\mathrm{mL}$ concentrations of $\mathrm{Tb}$-AgNPs in $3.4 \mathrm{~mL}$ phosphate buffer were added to $\mathrm{H}_{2} \mathrm{O}_{2}$ solution $(0.6 \mathrm{~mL}, 40 \mathrm{mM})$. The absorbance value of the reaction mixture was recorded at $230 \mathrm{~nm}$. The percent of scavenging of $\mathrm{H}_{2} \mathrm{O}_{2}$ was calculated using Eq. (2) as below:

$\operatorname{RSA}(\%)=[($ control absorbance - sample absorbance $) /$

control absorbance] $\times 100$.

\section{Nitric oxide (NO) scavenging activity}

The nitric oxide scavenging activity was measured by slightly modified methods [23]. The nitric oxide radicals (NO) were generated from sodium nitroprusside. $1 \mathrm{~mL}$ of sodium nitroprusside $(10 \mathrm{mM})$ and $1.5 \mathrm{~mL}$ of phosphate buffer saline $(0.2 \mathrm{M}, \mathrm{pH} 7.4)$ were added to different concentrations as of 25, 50, 75 and $100 \mu \mathrm{g} / \mathrm{mL}$ of $\mathrm{Tb}$-AgNPs and incubated for $150 \mathrm{~min}$ at $25^{\circ} \mathrm{C} ; 1 \mathrm{~mL}$ of the reaction mixture was treated with $1 \mathrm{~mL}$ of Griess reagent (1\% sulfanilamide, $2 \% \mathrm{H}_{3} \mathrm{PO}_{4}$ and $0.1 \%$ naphthylethylenediamine dihydrochloride). The absorbance of the chromatophore was measured at $546 \mathrm{~nm}$. Nitric oxide scavenging activity was calculated using Eq. (3):
$\operatorname{RSA}(\%)=[($ control absorbance - sample absorbance $) /$

control absorbance] $\times 100$.

\section{Anti-bacteriological activity}

The anti-bacteriological activity of Terminalia belerica fruit mediated $T b$-AgNPs was studied against antibiotic resistant bacteria, two different strains of Escherichia coli (E.coli Strain-I (Donor) rifampin resistant, E.coli AB1157 (Mutant) streptomycin resistant), and also against gram positive bacterium Pseudomonas aeruginosa and gram positive bacterium Staphylococcus aureus by disc procedure. Freshly prepared bacterial culture of all the above bacterial samples were grown in sterile nutrient broth (Himedia, $\mathrm{gm} / \mathrm{L}$ ) for overnight at $37^{\circ} \mathrm{C}$. $200 \mu \mathrm{L}$ of respective microbial cultures was spread on nutrient agar plates; sterile discs were placed on nutrient agar plates; the discs were prepared with Whatmann Grade 1 filter paper. The biosynthesized green $T b$-AgNPs were added onto the sterile discs with the help of micropipette as of $5 \mu \mathrm{L}$ ( $5 \mathrm{mcg}), 10 \mu \mathrm{L}(10 \mathrm{mcg}), 20 \mu \mathrm{L}(20 \mathrm{mcg})$ and $30 \mu \mathrm{L}(30 \mathrm{mcg})$, and Amoxyclav (30 mcg) disc was used as standard drug. The nutrient agar plates with the above samples were incubated at $37^{\circ} \mathrm{C}$ for overnight.

\section{Cell culture}

Cytotoxic activity of AgNPs by 3-(4,5Dimethylthiazol-2-yl)-2,5-diphenyltetrazolium bromide (MTT assay)

MCF-7 cells were purchased from the National Centre for Cellular Sciences (NCCS), Pune, India. MCF-7 cells were cultured in Eagle's minimum essential medium (EMEM), which consisted of 10\% fetal bovine serum heat inactivated, $2 \mathrm{mM}$ glutamine, 1 $\mathrm{mM} \mathrm{NaHCO}_{3}, 100 \mu \mathrm{g} / \mathrm{mL}$ streptomycin and 100 units/ $\mathrm{mL}$ penicillin. The MCF-7 cell lines were maintained in culture at $37^{\circ} \mathrm{C}$ in presence of $5 \% \mathrm{CO}_{2}$ atmosphere.

The cytotoxic activity of biosynthesized $T b$ AgNPs was measured by using MTT assay [24]. Momentarily, $2 \times 10^{4}$ MCF-7 cells were seeded in 96well plates containing $100 \mu \mathrm{L}$ of EMEM in each well. After overnight incubation of the MCF-7 cells, exactly $100 \mu \mathrm{L}$ of AgNPs at different concentrations (0, 10, $50,100,150$ and $200 \mu \mathrm{g} / \mathrm{mL}$ ) were added to the cells respectively. The plates were incubated for $24 \mathrm{~h}$; the viability of cells was examined by adding $10 \mu \mathrm{L}$ of MTT $(5 \mathrm{mg} / \mathrm{mL})$ per well and the plate was incubated at $37{ }^{\circ} \mathrm{C}$ for $3 \mathrm{~h}$. The 96 -well plates were centrifuged at $1000 \mathrm{xg}$ for $10 \mathrm{~min}$ at room temperature. The insoluble 
Formazan blue formed in the cells was dissolved by using $100 \mu \mathrm{L}$ of DMSO. The color intensity was measured at $570 \mathrm{~nm}$ wavelength. The percentage of inhibition of cell viability was determined and the $\mathrm{IC}_{50}$ value at which cell viability decreased by $50 \%$ were also calculated.

\section{Results and Discussion}

More than $80 \%$ of the world population rely on herbal medicines as over the counter herbal formulations and proprietary herbal drugs. The bioactive phyto-constituents from important and rare medicinal plants are widely used directly or indirectly in new drug formulations. So in the present study the Terminalia belerica fruit extract was used for the synthesis of $T b$-AgNPs. Terminalia belerica belongs to the family Combretaceace. The dried fruit has been used for centuries in Ayurveda, a holistic system of medicine originating from India [25]. The fruits are astringent, acrid, digestive, antihelmintic, expectorant, narcotic, ophthalmic, antipyretic, antiemetic and rejuvenating. The oil extract from the seed pulp is used for the treatment of leucoderma and alopecia [26]. It has important phytoconstituents; these compounds were found to be responsible for many of the pharmacological activities such as antimicrobial, antioxidant, antidiabetic, antidiarrhoeal, analgesic, immunomodulatory activities, etc. [27]. The biosynthesis of $T b$-AgNPs was carried out by green process using Terminalia belarica fruit powder extract by reduction process. Under ambient conditions, the silver nitrate solution was mixed with Terminalia belarica fruit extract; the reaction mixture turned from light yellow color to dark brown color within 2-5 min (Fig. 1), which indicated the formation of Tb-AgNPs. The bio-reduction was further confirmed by ultravioletvisible spectroscopy (UV-Vis).

\section{Ultraviolet-visible spectroscopy (UV-Vis) analysis of $T b$-AgNPs}

UV-Vis is a significant method for analysis and detection of the formation of $T b$-AgNPs in aqueous solutions. From the earlier reports, it was clearly understood that the silver nanoparticles exhibited different colors in aqueous solutions due to its characteristic surface plasmon resonance (SPR) vibrations [28-29]. The color of Tb-AgNPs in solution was due to the excitation of nanoparticles in UV-Vis, The color of $T b$-AgNPs colloidal solution changed from light brown to dark with the increase in time interval. The UV-Vis spectrum was depending on particle sizes and due to SPR absorption spectrum exhibited by the metal nanoparticles in the visible range [30]. The UV-Vis absorption (SPR) spectra of the biosynthesized $T b$-AgNPs by using Terminalia belarica fruit extract was observed at $430 \mathrm{~nm}$ (Fig. 2). The SPR peak reflected many physical factors such as size, shape and particle stability. Previous studies also revealed that the particles in SPR range of above 420 $\sim 450 \mathrm{~nm}$ were attributed to AgNPs of varying size ranges between 2 and $100 \mathrm{~nm}$ [31]. If SPR of AgNPs was between 410 and $450 \mathrm{~nm}$, it indicated that the biosynthesized AgNPs were spherical in shape [3233]. Similar results have already been reported in the case of stabilization effect of biological extracts on the formation of metal nanoparticles [34, 10-11]. Thus, in these studies, the formation and stability of nanoparticles were clearly understood by UVVis spectrum and SPR graph. Furthermore, the FTIR analysis confirmed the participation of different phytoconstituents in the synthesis of $T b$-AgNPs. EDX also revealed the percentage of elemental silver ions.

\section{FTIR analysis of $\mathbf{T b}$-AgNPs}

Terminalia belarica fruit extract consists of $40 \%$ tannins in beleric and $60 \%$ tannins in beleric myrobalan as active ingredient. The main chemical constitutes of tannins mainly include $\beta$-sitosterol, gallic acid, ellagic acid, ethyl gallate, galloyl glucose and chebulaginic acid apart from tannins. It also consists of different chemical constituents such as glycosides or sugars (fructose, sucrose and galactose), terpenoid (belleric acid and chebulagic acid) and saponin (bellericoside and bellericanin) [27]. So different concentration of different functional phytoconstituents of Terminalia belarica fruit may be responsible for capping and stabilizing the reduced nanoparticles. In the present study, the FTIR spectra of Terminalia belarica fruit extract and Tb-AgNPS are presented in Fig. 3. The $T b$-AgNPs exhibited clear infrared radiation (IR) absorption bands at wave numbers 3408.88, 2926.02, $1634.66,1414.68$, and 1010.10 . The sharp bands observed at 3408.88 and 2926.02 were attributed to stretching of $-\mathrm{O}-\mathrm{H}-$ hydroxyl and $\mathrm{C}-\mathrm{H}$ stretching modes in phenol vibrations. The IR absorption bands 1634.66 and 1414.68 were attributed to the COO asymmetric and symmetric stretching of aldehydes, alkenes and aromatics. From the above results, it was concluded that tannins and sugars were responsible for the reduction and stabilization of $T b$-AgNPs. The other IR functional groups present in the fruit extract might 


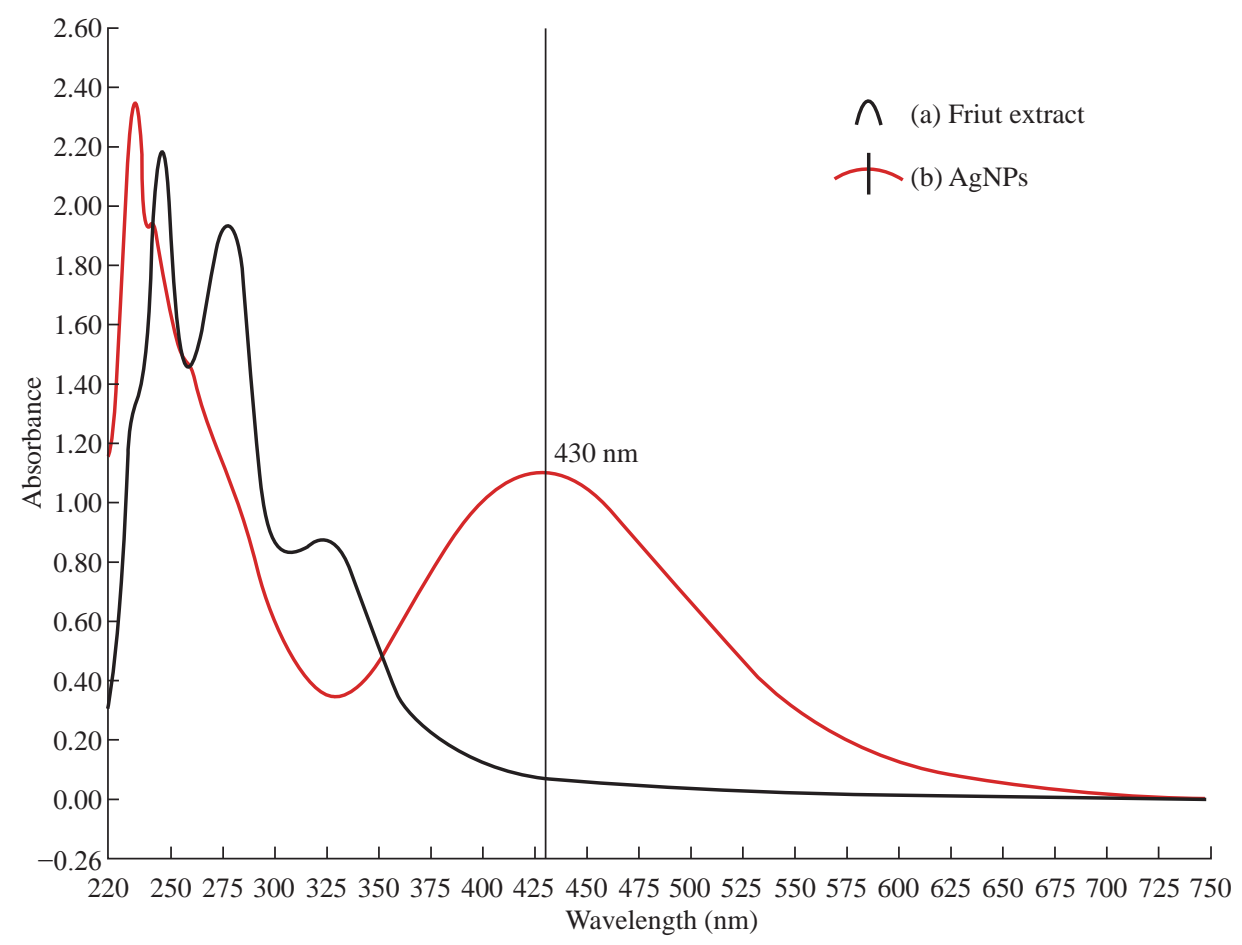

Fig. 2 (a) UV-Vis absorption spectra of Terminalia belarica fruit extract; (b) UV-Vis absorption spectra of Tb-AgNPs synthesized from Terminalia belarica fruit extract with $2 \times 10^{-3} \mathrm{M}$ silver nitrate.

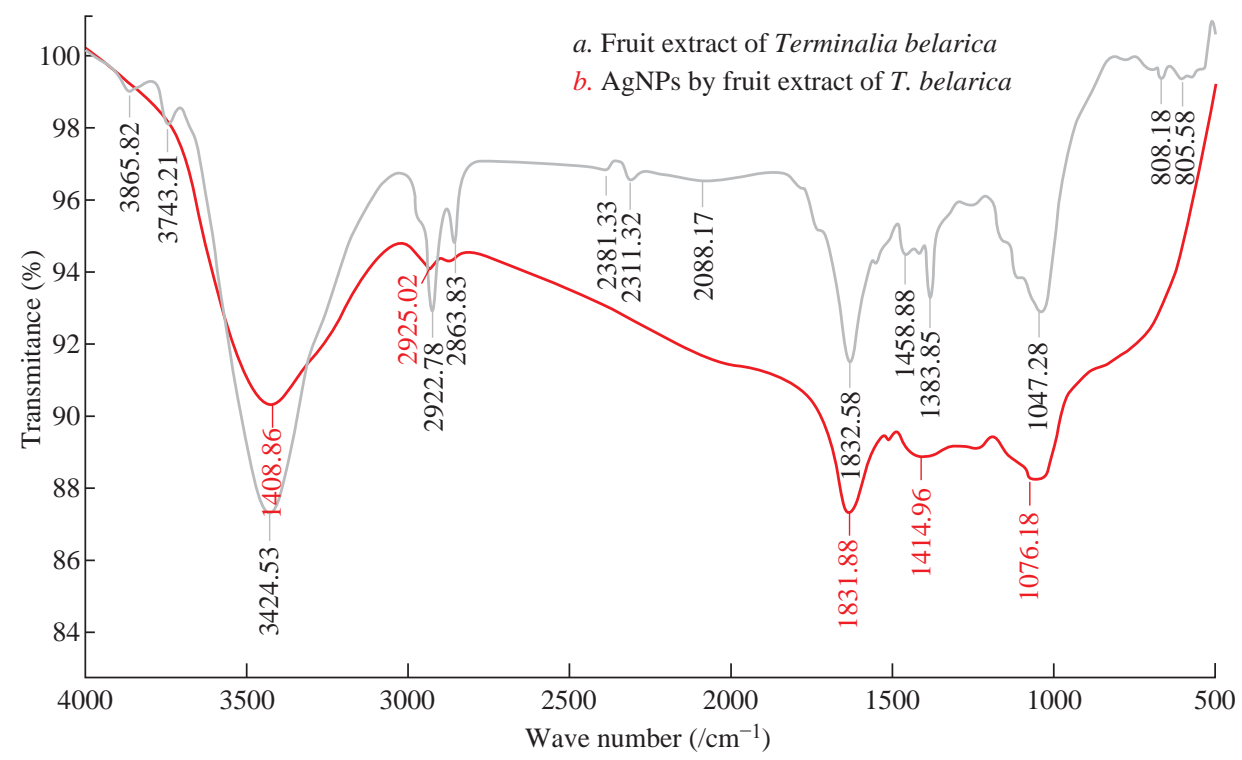

Fig. 3 (a) FTIR spectrum of Terminalia belarica fruit extract; (b) FTIR spectrum of the synthesized Tb-AgNPs.

also be responsible for the reduction $T b$-AgNPs [3539, 12-14].

\section{Energy-dispersive X-ray spectroscopy (EDX) analysis of $T b$-AgNPs}

EDX revealed a strong signal in the silver region and confirmed the formation of AgNPs which might have originated from the biomolecules bound to the surface of the AgNPs. The EDX analysis represented the presence of the elemental silver (Fig. 4). The EDX profile showed strong silver signal along with moderate peaks of carbon and oxygen and weak peaks of silicon, chloride and potassium which might originate from the biomolecules that were bound to the surface of $T b$ AgNPs, confirming the complete reduction of silver ions. Metallic silver nanocrystals generally showed typical optical absorption peak, approximately at 3 $\mathrm{keV}$ due to surface plasmon resonance [45]. It has been reported that nanoparticles synthesized using plant extracts are surrounded by a thin layer of some capping 


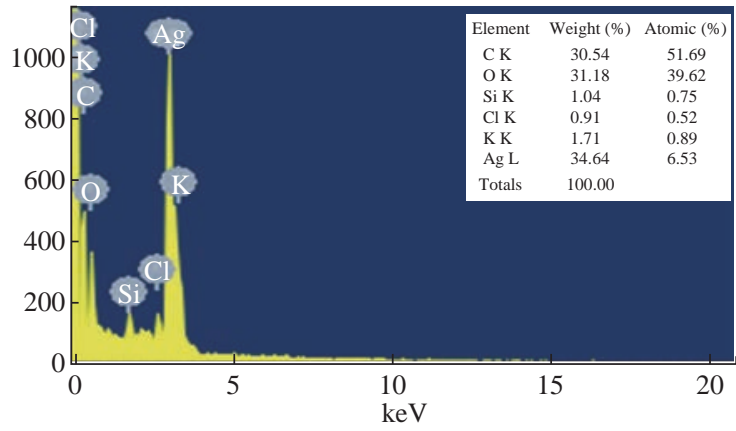

Fig. 4 EDX analysis of biofabricated $T b$-AgNPs by fruit extract of Terminalia belarica.

organic materials from the plant leaf broth, so they are stable in solution up to 4 weeks after synthesis [46]. Silver (34.64\%) was the major constituent element compared to carbon (30.54\%) oxygen (31.18\%), silicon $(1.04 \%)$, chloride $(0.91 \%)$, and potassium (1.71\%) (Fig. 4). The spectrum around $3 \mathrm{keV}$ indicated a characteristic strong signal for nano-sized particles of silver. There were no peaks for silver compounds observed, which suggested that the silver compound was reduced completely to $\mathrm{Tb}$-AgNPs as determined by the spectrum.

\section{Particle size determination of $\mathrm{Tb}$-AgNPs}

The DLS data revealed information about the size distribution of biosynthesized Tb-AgNPs by measuring their effects in light scattering due to Brownian motion of silver nanoparticles in liquid solution. The size of biosynthesized $T b$-AgNPs was detected by dynamic light intensity and laser diffraction method. The biosynthesized $T b$-AgNPs were poly-dispersed in nature. The DLS particle size data analysis revealed that the Terminalia belarica fruit extract $\mathrm{Tb}$-AgNPs formed in the range of $15 \sim 90 \mathrm{~nm}$. The average size (hydro dynamic radius) of the biosynthesized $T b$ AgNPs was detected to be $46.5 \mathrm{~nm}$ (Fig. 5). Similar results were observed in TEM analysis and the average size of the $T b$-AgNPs was in the range of 15 to $45 \pm 5$ nm.

\section{Analysis of Zeta potential of green $\mathbf{T b}$-AgNPs}

Zeta potential is an important parameter which indicates the charge of the nanoparticles in a particular medium. In general, nanoparticles have charge on the surface, which generates repulsive forces between nanoparticles. The value recorded for the Terminalia belarica fruit extract biosynthesized silver nanoparticles was $-29.2 \mathrm{mV}$ (Fig. 6). This indicated that the AgNPs surface was negatively charged. Due to the presence of negative charge on the surface, agglomeration of $T b$-AgNPs in aqueous solution was prevented, and long-term stability was also allowed. This clearly indicated that the nanoparticles were stable because the minimum charge required to stabilize the nanoparticles was $+30 \mathrm{mV}$ or $-30 \mathrm{mV}$ [40, 13-14]. The results revealed and concluded that the biosynthesized Tb-AgNPs with the fruit extract of Terminalia belarica were very stable in aqueous environment.

\section{Transmission electron microscopy (TEM) analysis and selected area electron diffraction (SAED) pattern of Tb-AgNPs}

Further studies were carried out with TEM to

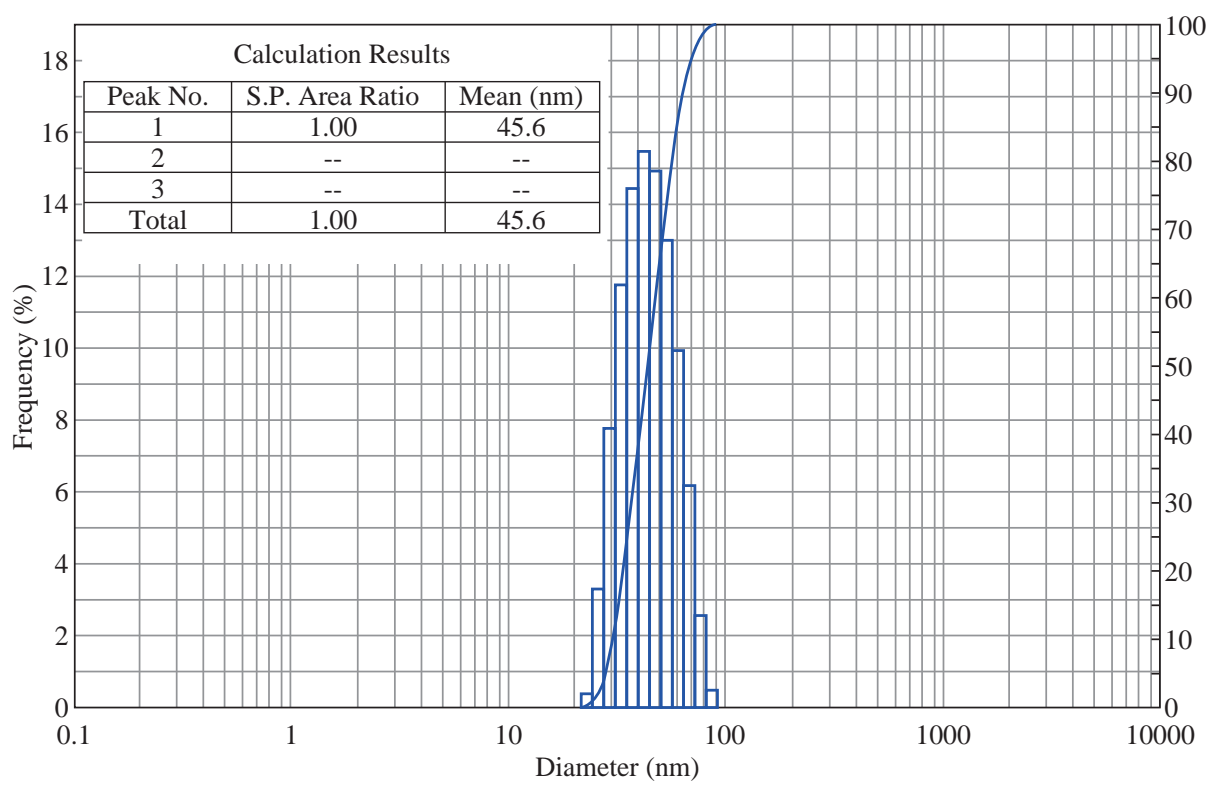

Fig. 5 Particle size distribution curve for Tb-AgNPs. 
determine the structural properties, such as the size and the shape, of biosynthesized $T b$-AgNPs by the fruit extract of Terminalia belarica. From the TEM micrographs at different magnifications, it was clearly understood that $\mathrm{Tb}$-AgNPs were spherical in shape, their sizes ranged from 10 to $45 \pm 5 \mathrm{~nm}$, and they were poly-dispersed in nature. The scale bar of TEM micrograph of biosynthesized Tb-AgNPs at $50 \mathrm{~nm}$ was represented in Fig. 7. The TEM images were in good agreement with the results obtained by UVVis spectroscopy. The biosynthesized Tb-AgNPs in aqueous solution were aggregated to some extent, but were unvarying in size and stable. The results were consistent with earlier reports of biosynthesized AgNPs from different plant-mediated sources [41, 15]. The SAED pattern of biosynthesized Tb-AgNPs by the fruit extract of Terminalia belarica shown in Fig.7(d) represented polycrystalline diffraction rings corresponding to distinct diffraction rings of the (111), (200), (220), (311) and (222) planes, indicating that the biosynthesized $T b$-AgNPs were highly crystalline in nature.

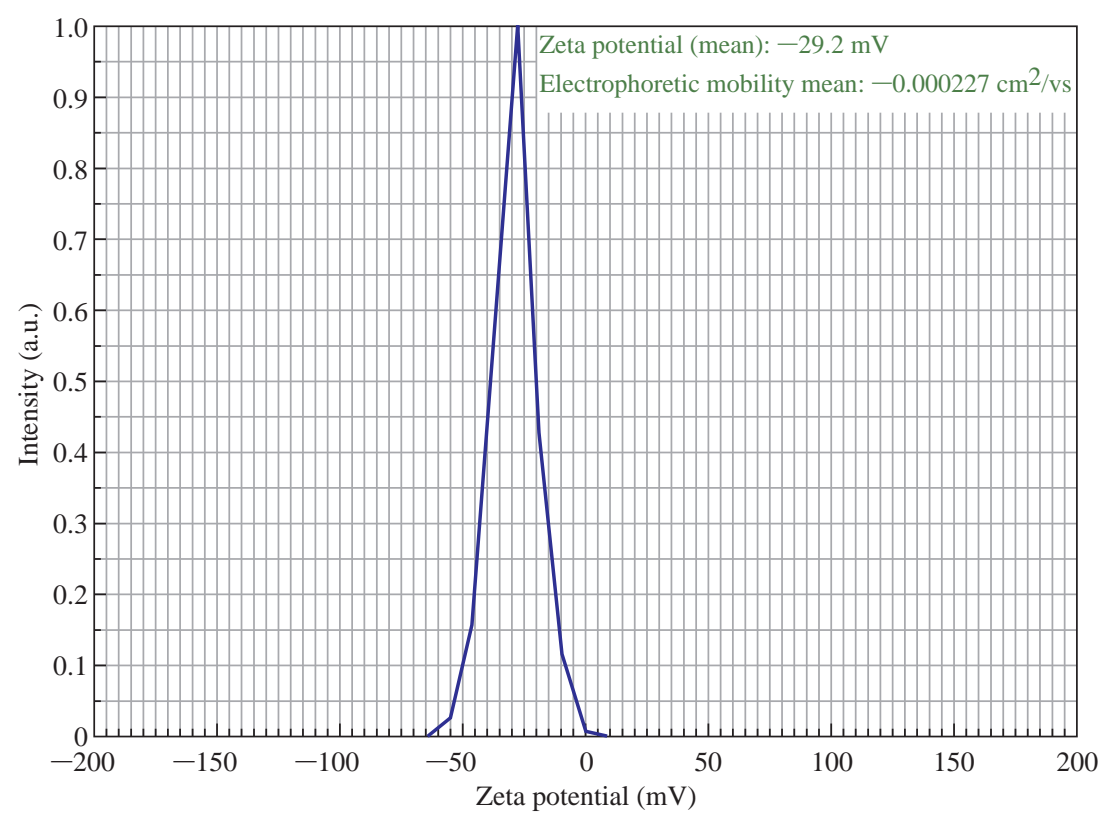

Fig. 6 Zeta potential of synthesized Tb-AgNPs.
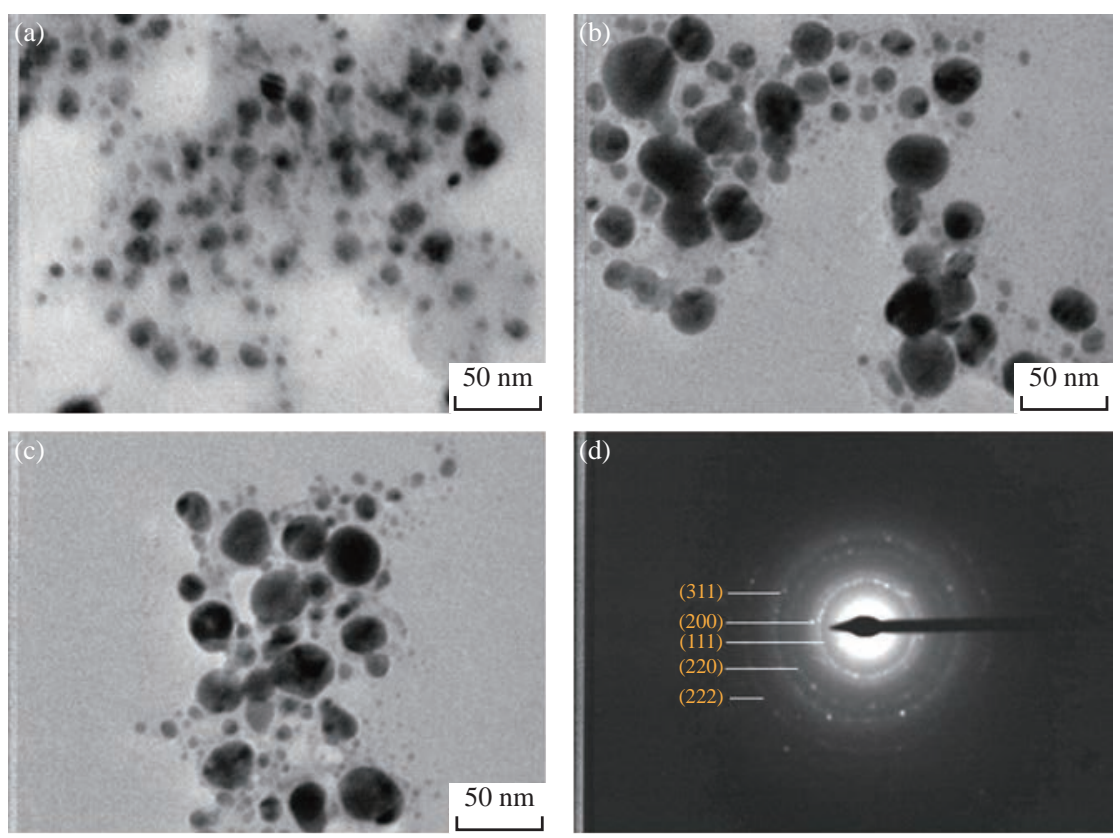

Fig. 7 TEM images of Tb-AgNPs at magnification of (a) $\times 200 \mathrm{~K}$, (b) $\times 360 \mathrm{~K}$ and (c) $\times 500 \mathrm{~K}$; (d) SAED pattern showed five diffraction rings. 


\section{X-ray diffraction (XRD) analysis of Tb-AgNPs}

The size and crystalline nature of biosynthesized Tb-AgNPs of Terminalia belarica fruit extract were evaluated using XRD. The results of XRD analysis is shown in Fig. 8 which reveals five distinctive diffraction peaks at $38.31^{\circ}, 44.61^{\circ}, 64.50^{\circ}, 77.58^{\circ}$ and $83.35^{\circ}$, corresponding to planes of (111), (200), (220), (311) and (222), respectively. The planes were indexed according to the facets of face centered cubic (fcc) crystal structure of silver (JCPDS card no. 870719). The XRD pattern was consistent with previous reports [42, 29]. At the same time, the results were in accordance with SAED pattern analysis of TEM, representing the planes of crystalline diffraction rings corresponding to (111), (200), (220), (311) and (222) (Fig. 8). That the diffraction peaks were consistent indicated the $T b$-AgNPs were crystalline in nature. These results were also in accordance with studies of other researchers [43-44].

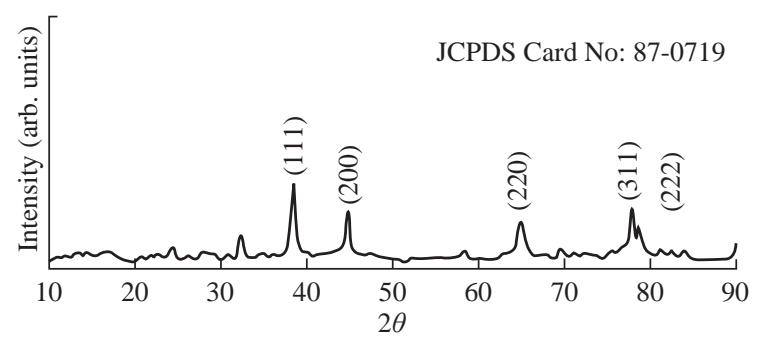

Fig. 8 XRD spectral data of biosynthesized Tb-AgNPs.

\section{Atomic force microscopy (AFM) studies of $T b$ - AgNPs}

AFM is an advanced spectroscopic technique used to explore and determine the morphology and topology of biosynthesized $T b$-AgNPs. The results disclosed that biosynthesized $T b$-AgNPs appeared to be spherical in shape by showing the nanoparticle's topology and morphology (Fig. 9). Nova-Px 3.2.0. Rev software provided by NT-MDT was used to detect the grain size of the AFM image. An analysis of the results revealed that $T b$-AgNPs were varied in size from $6 \pm 5 \mathrm{~nm}$ to 45 $\pm 5 \mathrm{~nm}$, whereas the average size of grains was found to be $46.5 \mathrm{~nm}$. We also carried out grain analysis of the AFM 3D image using Nova-Px 3.2.0. Rev software by means of $\mathrm{Z}$ coloration technique which showed the range of nanoparticle size distributed within the 3D image by color differentiation (Fig. 10). No previous studies reported the $\mathrm{Z}$ coloration technique; we were the first to have reported this type of methodology for analysis of grain size of biosynthesized Tb-AgNPs.

\section{2,2-diphenyl-1-picrylhydrazyl (DPPH) antioxidant activity of $\mathrm{Tb}$-AgNPs}

The antioxidant activity of biosynthesized $\mathrm{Tb}$ AgNPs was detected by DPPH method. The DPPH free radical activity depends on the reduction of DPPH radical from DPPH to DPPH-H, a hydrogen-donating antioxidant. The in-vitro antioxidant activity and half maximal inhibitory concentration $\left(\mathrm{IC}_{50}\right)$ values of the Terminalia belarica fruit extract biosynthesized $T b$ AgNPs were reported in Table 1. The results revealed that the antioxidant free radical scavenging activity increased with the concentration of test samples. In the present experiment, it was determined that the free radical scavenging activity of biosynthesized $\mathrm{Tb}$-AgNPs at the concentration of $100 \mu \mathrm{g} / \mathrm{mL}$ was 72.21 ; the value is $67.43 \pm 0.67$ for standard ascorbic acid and $68.10 \pm 1.24$ for aqueous fruit extract of Terminalia belarica. Therefore, it was concluded that the biosynthesized $T b$-AgNPs proved to be the most effective scavenging agent. The oxidant activity of $T b$ AgNPs was on par with standard ascorbic acid.

The $\mathrm{IC}_{50}$ value of all the test samples was also calculated, which was equivalent to $50 \%$ of the free

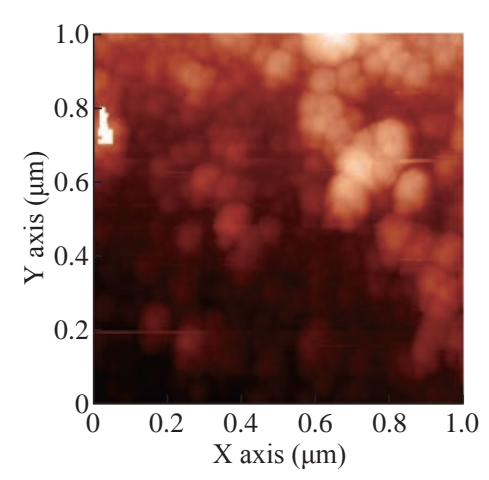

(a) $2 \mathrm{D}$ image

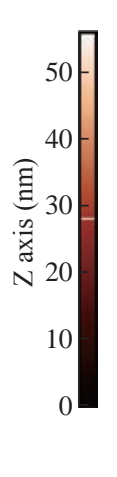

Fig. 9 2D images of (a) synthesized Tb-AgNPs and (b) grains detected.
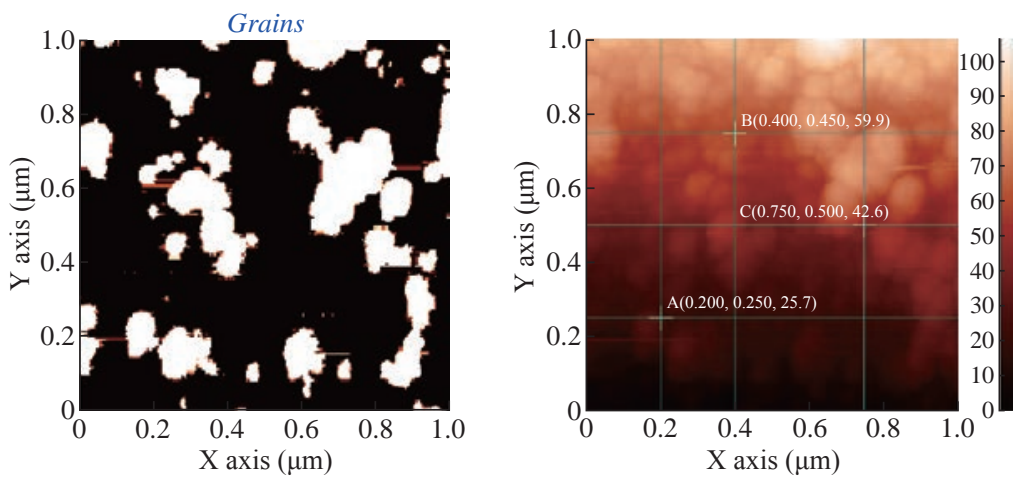


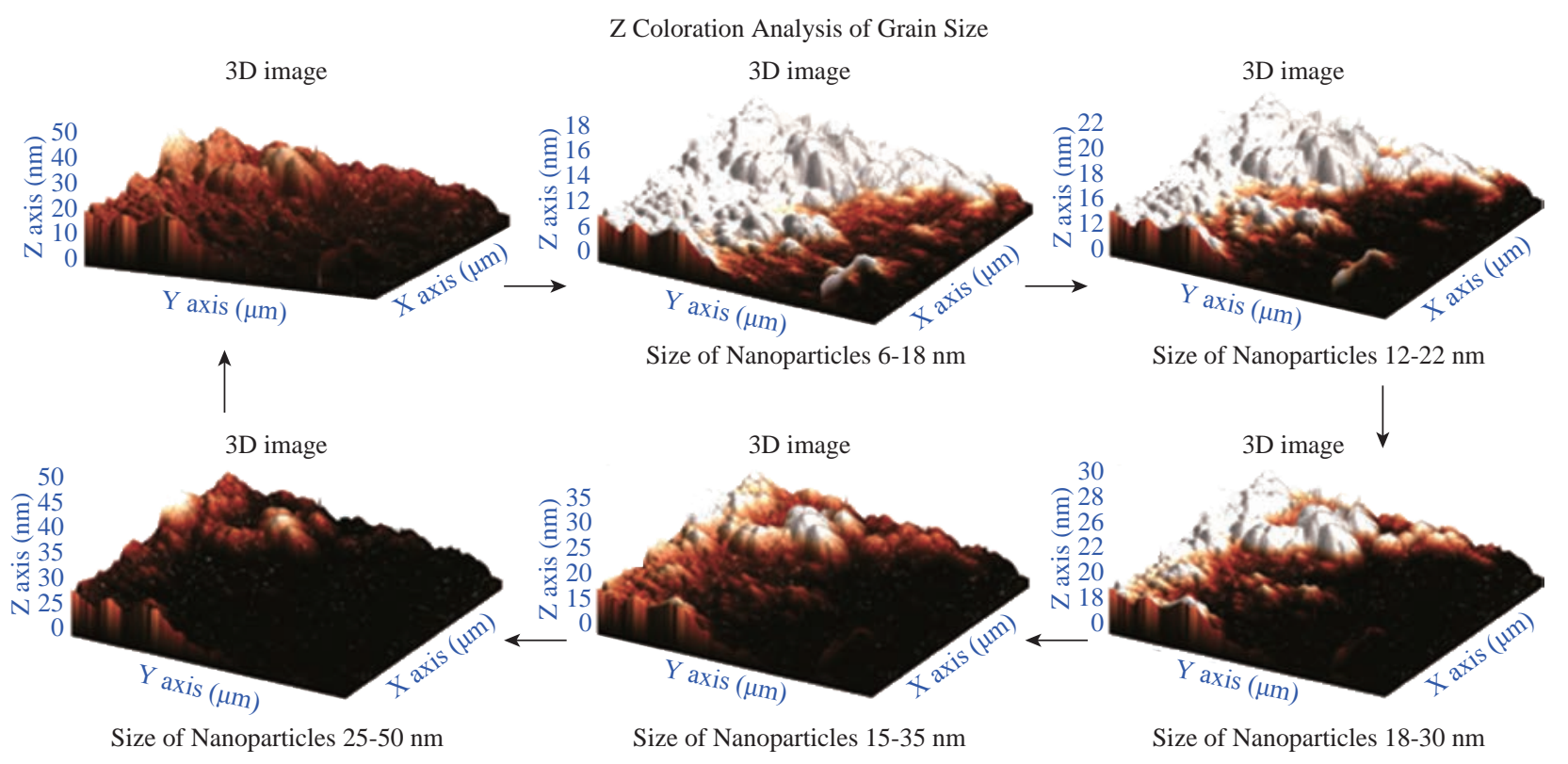

Fig. 10 3D images of synthesized AgNPs and grain analysis of Tb-AgNPs by Z coloration method.

Table 1 (i) Free radical scavenging activity of silver nanoparticles by DPPH method; (ii) In-vitro antioxidant activity by $\mathrm{H}_{2} \mathrm{O}_{2}$ method; and (iii) In-vitro antioxidant activity by nitric oxide (NO) method.

\begin{tabular}{|c|c|c|c|c|c|}
\hline \multicolumn{5}{|c|}{ Free radical scavenging activity $\pm \mathrm{SD}(\%)$} & \multirow[b]{2}{*}{$\mathrm{IC}_{50}$} \\
\hline Sample name & $25 \mu \mathrm{g} / \mathrm{mL}$ & $50 \mu \mathrm{g} / \mathrm{mL}$ & $75 \mu \mathrm{g} / \mathrm{mL}$ & $100 \mu \mathrm{g} / \mathrm{mL}$ & \\
\hline Ascorbic acid & $45.07 \pm 0.26$ & $54.73 \pm 0.07$ & $63.54 \pm 0.56$ & $67.43 \pm 0.67$ & $33.93 \pm 0.12$ \\
\hline Terminalia belarica fruit extract & $15.25 \pm 1.25$ & $41.46 \pm 1.84$ & $65.48 \pm 1.32$ & $68.10 \pm 1.24$ & $60.29 \pm 1.38$ \\
\hline AgNPs & $27 \pm 1.45$ & $52.91 \pm 0.36$ & $66.24 \pm 1.45$ & $72.21 \pm 0.19$ & $47.25 \pm 0.17$ \\
\hline (ii) $\mathrm{H}_{2} \mathrm{O}_{2}$ method & \multicolumn{4}{|c|}{ Free radical scavenging activity \pm SD $(\%)$} & \\
\hline Sample name & $25 \mu \mathrm{g} / \mathrm{mL}$ & $50 \mu \mathrm{g} / \mathrm{mL}$ & $75 \mu \mathrm{g} / \mathrm{mL}$ & $100 \mu \mathrm{g} / \mathrm{mL}$ & $\mathrm{IC}_{50}$ \\
\hline Terminalia belarica fruit extract & $9.27 \pm 0.41$ & $21.6 \pm 1.29$ & $37.45 \pm 1.45$ & $44.21 \pm 1.33$ & $21 \pm 1.44$ \\
\hline AgNPs & $18.03 \pm 0.27$ & $36.18 \pm 0.9$ & $47.54 \pm 0.56$ & $52.33 \pm 0.7$ & $24.5 \pm 0.58$ \\
\hline (iii) NO method & \multicolumn{4}{|c|}{ Free radical scavenging activity $\pm \mathrm{SD}(\%)$} & \\
\hline Sample name & $25 \mu \mathrm{g} / \mathrm{mL}$ & $50 \mu \mathrm{g} / \mathrm{mL}$ & $75 \mu \mathrm{g} / \mathrm{mL}$ & $100 \mu \mathrm{g} / \mathrm{mL}$ & $\mathrm{IC}_{50}$ \\
\hline Terminalia belarica fruit extract & $10.73 \pm 1.7$ & $27.3 \pm 0.17$ & $42.51 \pm 0.7$ & $57.33 \pm 0.88$ & $28.6 \pm 0.76$ \\
\hline AgNPs & $27.39 \pm 1.13$ & $33.22 \pm 1.51$ & $54.27 \pm 1.3$ & $61.81 \pm 0.69$ & $26 \pm 01.44$ \\
\hline
\end{tabular}

radicals in tested samples. In the present study, the $\mathrm{IC}_{50}$ values of biosynthesized $\mathrm{Tb}$-AgNPs and fruit extract of Terminalia belarica were found to be $47.25 \pm 0.17 \mu \mathrm{g} /$ $\mathrm{mL}$ and $60.29 \pm 1.38 \mu \mathrm{g} / \mathrm{mL}$, respectively (Fig.11(a)). It was previously known that the lesser the $\mathrm{IC}_{50}$ value, the more the scavenging activity. So it could be concluded that the biosynthesized AgNPs had effective free radical scavenging activity when compared with the fruit extract.

The biosynthesized Tb-AgNPs by Terminalia belarica aqueous fruit extract actually consist of different secondary metabolites including flavonoids, terpenoids, polyphenols, proteins, etc. The secondary metabolites can easily donate hydrogen atoms, thus increasing the free scavenging activity of biosynthesized $T b$-AgNPs, which in turn are actively involved in the stabilization of Tb-AgNPs. This was also confirmed by FTIR results in the present study. The results were similar to those that of earlier reports on biosynthesis of AgNPs [47]. It is also understood that less antioxidants lead to imbalance of ROS, which can increase oxidative stress in order to produce 
inflammation, atherosclerosis, neurodegenerative disorders, aging and cancer [47].

\section{Hydrogen peroxide scavenging assay of $\mathbf{T b}$ - AgNPs}

Accumulation of uninhibited $\mathrm{H}_{2} \mathrm{O}_{2}$ in living cells leads to the increase of reactive oxygen species or oxygen free radicals such as peroxides and hydroxyl, which causes vast injure to cell membranes. In the present study, hydrogen peroxide scavenging activity of $\mathrm{Tb}$-AgNPs was carried out and quantified, as shown in Table 1 and Fig. 11(b). The inhibition concentrations at $100 \mu \mathrm{g} / \mathrm{mL}$ were found to be $52.33 \pm 0.7 \%$ and 44.21 $\pm 1.33 \%$ for the biosynthesized $T b$-AgNPs and fruit extract of Terminalia belarica, respectively. The $\mathrm{H}_{2} \mathrm{O}_{2}$ free radical was consistently lower than those obtained for DPPH scavenging activity. The biofabricated $T b$ AgNPs dispersed in the presence of hydrogen peroxide could stimulate reactive oxygen species such as hydroxyl radicals and produce much stronger oxidative stress. The present results were in accordance with earlier reports of $\mathrm{H}_{2} \mathrm{O}_{2}$ scavenging effect of different plant extracts [48-50]

\section{Nitric oxide (NO) radical scavenging assay of Tb-AgNPs}

The NO scavenging activity of biosynthesized
Tb-AgNPs and fruit extract of Terminalia belarica, showed the highest activity at the concentration of 100 $\mu \mathrm{g} / \mathrm{mL}$, i.e. $61.81 \pm 0.69$ and $54.27 \pm 1.3$, respectively (Table 1, Fig. 11(c)). The above observed NO activity was higher than that of the $\mathrm{H}_{2} \mathrm{O}_{2}$ scavenging activity, whereas was lower than that of DPPH activity. In the biology system, nitric oxide is a very important bioregulatory molecule in various systems like immune system, nervous system and cardiovascular system [51]. The nitric oxide free radicals are very unstable in nature, since the production of free radicals may be due the interaction of AgNPs and nitric oxide under anhydrous condition at room temperature [52]. So we could conclude that the antioxidant potential of $\mathrm{Tb}$-AgNPs could be attributed to functional groups adhered to them which were originated from the fruit extract of Terminalia belarica. Likewise, several other scientists studied the antioxidant activity of AgNPs biosynthesized from different parts of different plant materials [53]. Nitric oxide radical scavenging activity results revealed that the biosynthesized $T b$-AgNPs from fruit extract of Terminalia belarica could be used in future antioxidant formulations.

\section{Antimicrobial activity}

The bio-fabricated $T b$-AgNPs were found very effective against four different bacterial species at
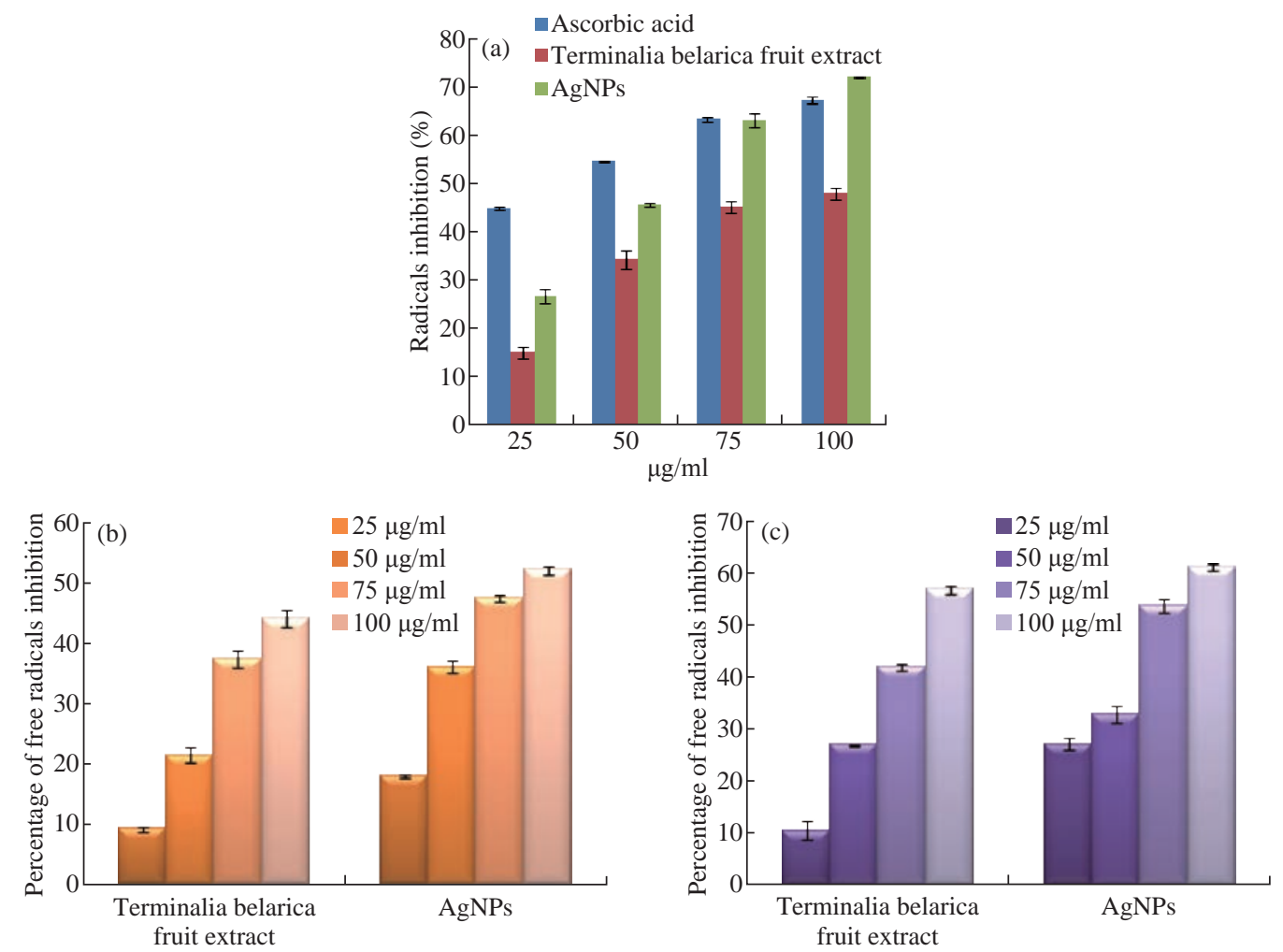

Fig. 11 (a) Free radical scavenging activity of biofabricated Tb-AgNPs by DPPH method; (b) Free radical scavenging activity of biofabricated $\mathrm{Tb}$-AgNPs by $\mathrm{H}_{2} \mathrm{O}_{2}$ method; (c) Free radical scavenging activity of biofabricated $T b$-AgNPs by no method. 
different concentrations of $5,10,20$ and $30 \mu \mathrm{L}$ of AgNPss on different gram +ve and gram -ve bacterial strains. The gram -ve bacteria Escherichia coli is antibiotic resistant bacteria; Pseudomonas aeruginosa and gram +ve Staphylococcus aureus bacteria are non-antibiotic resistant bacteria. The results showed excellent antimicrobial activity against Escherichia coli donor strain, Escherichia coli (E. coli) mutant strain and Pseudomonas aeruginosa; moderate activity was observed against Staphylococcus aureus gram +ve strain. The inhibitory behavior of Tb-AgNPs is shown in Table 2 and Fig. 12, by comparing with standard drug Amoxyclav. Hence, in the present study, $T b-$
AgNPs synthesized using silver nitrate and fruit extract of Terminelia belarica showed excellent bactericidal activity. Moreover, recent studies have revealed that the biosynthesized $T b$-AgNPs of round or spherical shape, size of and above $20 \mathrm{~nm}$ showed competent antibacterial activity against Escherichia coli and Staphylococcus aureus [54]. AgNPs have unique chemical and physical properties and high surface area to volume ratio due to the above properties; AgNPs have emerged as new antimicrobial agents [55]. In the current study, biosynthesized Tb-AgNPs with the fruit extract of Terminelia belarica were found to have excellent bactericidal activity. When added

Table 2 Antibacterial activity of biosynthesized silver nanoparticles

\begin{tabular}{|c|c|c|c|c|c|}
\hline & \multicolumn{4}{|c|}{ Different concentrations of AgNPs by Terminalia balerica fruit extract } & \multirow{2}{*}{$\begin{array}{c}\text { Control: Amoxyclav antibiotic } \\
30\end{array}$} \\
\hline $\begin{array}{l}\text { Concentration } \\
\text { of AgNPs (mcg) }\end{array}$ & 5 & 10 & 20 & 30 & \\
\hline Bacterial species & \multicolumn{5}{|c|}{ Zone of inhibition (mm) } \\
\hline $\begin{array}{l}\text { Escherichia coli strain I (donor) } \\
\text { rifampin resistant }\end{array}$ & 12 & 13 & 15 & 20 & 15 \\
\hline $\begin{array}{l}\text { Escherichia coli AB } 1157 \text { (mutant) } \\
\text { streptomycin resistant }\end{array}$ & 10 & 10 & 14 & 21 & 15 \\
\hline Pseudomonas aeruginosa & 9 & 12 & 15 & 21 & 14 \\
\hline Staphylococcus aureus & 9 & 10 & 12 & 14 & 12 \\
\hline
\end{tabular}
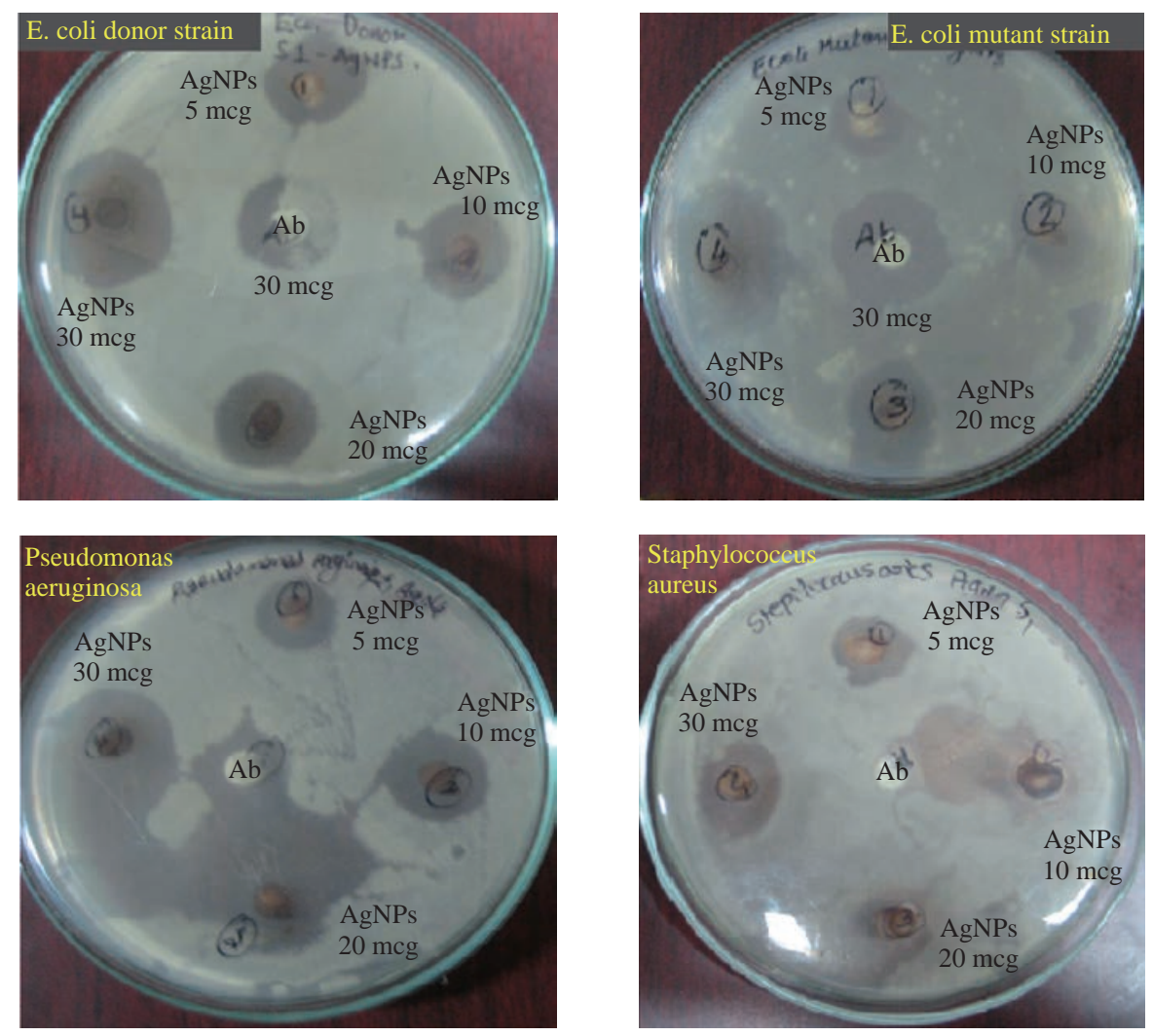

Fig. 12 Antimicrobial activity of $T b$-AgNPs on gram +ve and gram -ve bacteria. 
to different bacterial strains, the $T b$-AgNPs enter the bacteria by endocytosis and diffusion through the cell wall into the cytoplasm. The Tb-AgNPs induce toxicity in the bacterial cell. In sequence, the ROS along with Tb-AgNPs acts on nucleus of the bacteria, which stimulates the oxidation of nucleus and also induces chromosomal aberrations, eventually causing the death of the bacteria. Our present study led to the progress of new antibiotics against multidrug resistant bacteria with simple economical, eco-friendly green synthesis.

\section{Cytotoxic activity of $\mathrm{Tb}$-AgNPs on MCF-7 cancer cells}

Biocompatibility is crucial for the successful application of AgNPs in biomedical field. Hence, the Tb-AgNPs were evaluated for their cytotoxic effects on cancer cells breast cancer cell lines MCF-7. The percentage of cell viability of MCF-7 cell lines used in this study is depicted in (Fig. 13). Tb-AgNPs did show dose dependant increase in cytotoxicity against MCF7 cancer cells. It was observed that the percentage of cell viability decreased as the dosage of $\mathrm{Tb}$ AgNPs increased against cancer cells. Increase in the concentration of $\mathrm{Tb}$-AgNPs reduced the cell viability and increased the cytotoxicity against MCF-7 cell lines, $T b$-AgNPs effectively exhibited dose dependant cytotoxicity against cancer cells. Decrease in the cell viability and increase in the cytotoxicity were clearly observed as the concentration of $T b$-AgNPs increased against cancer cells. Tb-AgNPs showed 73.3\% inhibition of MCF-7 cells at $100 \mu \mathrm{g} / \mathrm{mL}$ concentration of $\mathrm{Tb}$-AgNPs in the present study. $\mathrm{IC}_{50}$ of $\mathrm{Tb}$-AgNPs against MCF-7 cancer cells was found to be $73.18 \mu \mathrm{g} /$ $\mathrm{mL}$. From the results, it was clear that MCF-7 cells were more susceptible to $T b$-AgNPs as tested in this study. The cytotoxic activity of $\mathrm{Tb}$-AgNPs at different concentrations against MCF-7 cells is depicted in Fig. 13. It clearly showed the increase in cytotoxicity with the increase in $T b$-AgNPs concentration.

The conceivable mechanism of the anticancer activity of $\mathrm{Tb}$-AgNPs is explained as follows and illustrated in Schematic 2.

The AgNPs entered into mammalian cells through various mechanisms such as endocytosis, pinocytosis and phagocytosis. Inside the cells, AgNPs interrupted various metabolic pathways by interacting with essential proteins; they could interact with the cellular DNA and cause DNA damage and finally lead to cell death [56]. It was also reported that the inhibitory effects of AgNPs on different cell lines mainly depended on the size, the morphology and the plant compound coated around AgNPs (proteins, polyphenols, tanins and flavonoids, etc). Our results are in line with other Tb-AgNPs synthesized from different plant extracts. AgNPs synthesized from leaf extract of Annona squamosa showed cytotoxicity against MCF-7 [57]. Based on the above results, it is apparent that the biosynthesized $T b$-AgNPs are biocompatible and toxic to cancer cells, and therefore AgNPs can be useful as
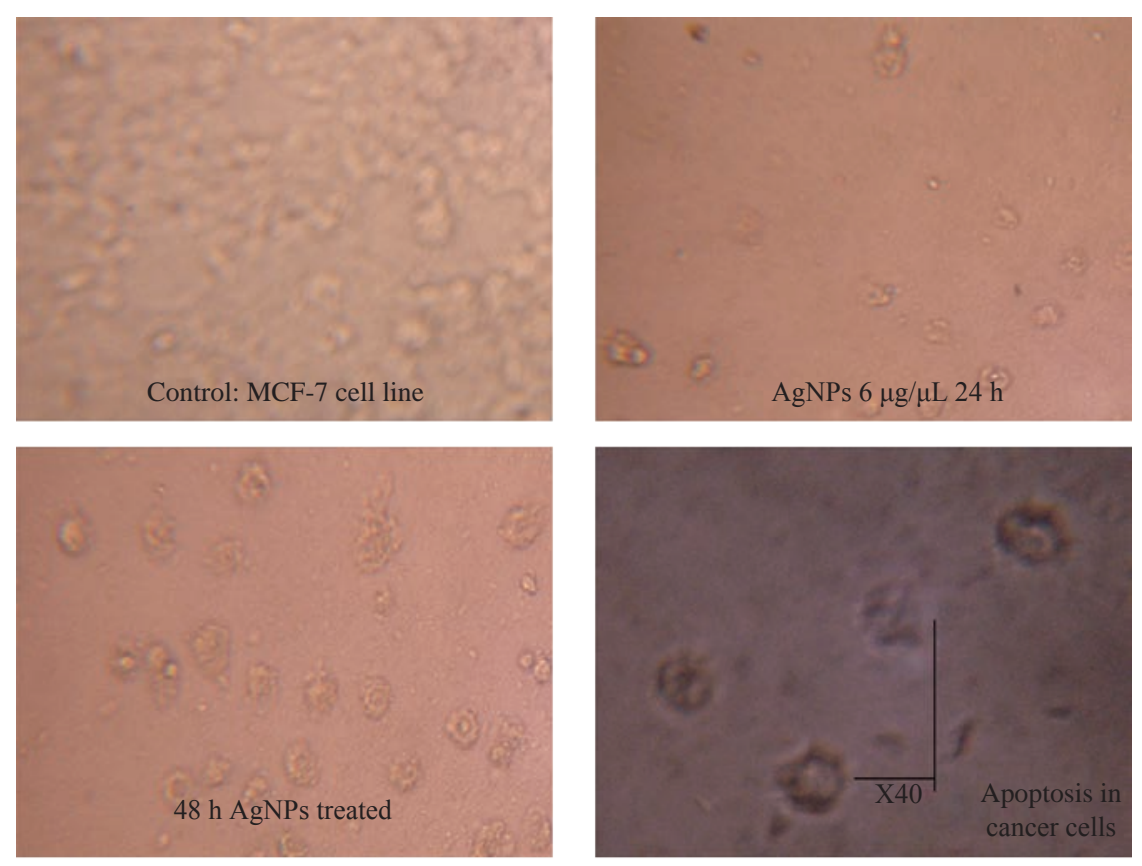

Fig. 13 Cytotoxic effect of Tb-AgNPs on MCF-7 human breast cancer cell. 


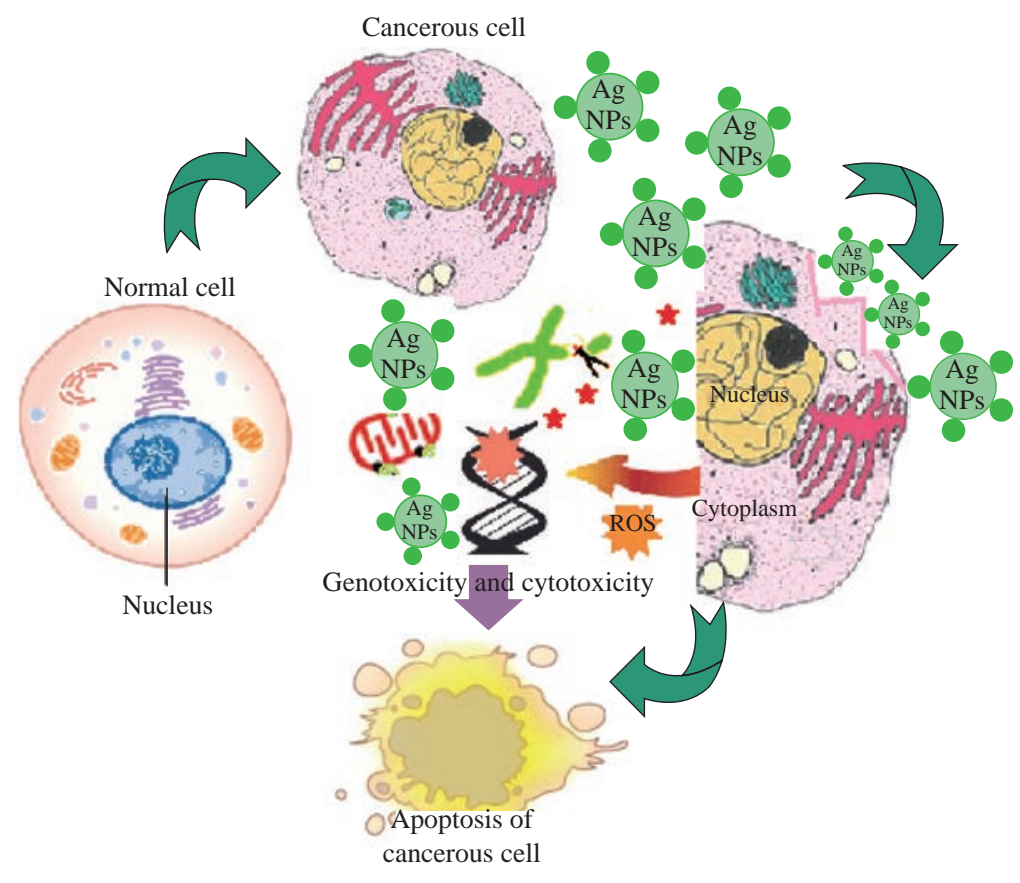

Schematic 2 Mechanism of the anticancer activity of $\mathrm{Tb}$-AgNPs.

potential anticancer agents.

\section{Conclusions}

The current study revealed that the biosynthesized Tb-AgNPs with the fruit extract of Terminelia belarica showed excellent multifunctional therapeutic properties such as antioxidant, antibacterial and anticancer activities. It was clearly evident that the metal nanoparticles smaller than $100 \mathrm{~nm}$ had very good biomedical applications.

\section{Acknowledgement}

The author Venkata Subbaiah Kotakadi is grateful to Department of Science and Technology-Promotion of University Research and Scientific Excellence (DSTPURSE) Programme, sponsored by Department of Science and Technology, New Delhi, for providing fellowship.

\section{Authors' contributions}

Sucharitha Kumaram Venkata, Susmila Aparna Gaddam, and Venkata Subbaiah Kotakadi contributed equally to the work.

\section{Conflict of Interests}

The authors declare that no competing interest exists.

\section{References}

[1] K.N. Thakkar, S.S. Mhatre, and R.Y. Parikh, Biological synthesis of metallic nanoparticles. Nanomedicine: Nanotechnology, Biology and Medicine. 2009, 6: 257 262.

[2] M.A. Dar, A. Ingle, and M. Rai, Enhanced antimicrobial activity of silver nanoparticles synthesized by Cryphonectria sp. evaluated singly and in combination with antibiotics. Nanomedicine: Nanotechnology, Biology and Medicine. 2013, 9: 105-110.

[3] M.S. Akhtar, J. Panwar, and Y.S. Yun, Biogenic synthesis of metallic nanoparticles by plant extracts. ACS Sustain. Chem. Eng., 2013, 1: 591-602.

[4] N.Vaidyanathan, K. Kalishwaralal, S. Gopalram, et al., Nanosilver -- the burgeoning therapeutic molecule and its green synthesis. Biotechnol. Adv., 2009, 27: 924-937.

[5] D. Hebbalalu, J. Lalley, M.N. Nadagouda et al., Greener techniques for the synthesis of silver nanoparticles using plant extracts, enzymes, bacteria, biodegradable polymers, and microwaves. ACS Sustain. Chem. Eng., 2013, 1: 703712

[6] O.V. Kharissova, H.V. Dias, B.I. Kharisov, et al., The greener synthesis of nanoparticles. Trends Biotechnol., 2013, 31: 240-248.

[7] M.C. Moulton, L.K. Braydich-Stolle, M.N. Nadagouda et al., Synthesis, characterization and biocompatibility of "green" synthesized silver nanoparticles using tea polyphenols. Nanoscale, 2010, 2: 763-770.

[8] M.N. Nadagouda, R.S. Varma, Green synthesis of silver and palladium nanoparticles at room temperature using coffee and tea extract. Green Chem., 2008, 10: 859-862.

[9] K.B. Narayanan, N. Sakthivel, Biological synthesis of metal nanoparticles by microbes. Adv. Colloid Interface Sci., 2010, 156(1-2): 1-13

[10] V.S. Kotakadi, Y. Subba Rao, S.A. Gaddam, et al., Simple and rapid biosynthesis of stable silver nanoparticles using dried leaves of Catharanthus roseus. Linn. G. Donn and its anti microbial activity. Colloids Surf. B: Biointerfaces. 2013, 105: 194-198.

[11] V.S. Kotakadi, Y. Subba Rao, Gaddam SA, et al., 
Biofabrication of silver nanoparticles by Andrographis paniculata. Eur J Med Chem., 2013, 73: 135-140.

[12] V.S. Kotakadi, S.A. Gaddam, S.K.Venkata, et al., Ficus fruit-mediated biosynthesis of silver nanoparticles and their antibacterial activity against antibiotic resistant E.coli strains. Curr Nanosci, 2015, 11(4): 527-538.

[13] V.S. Kotakadi, S.A. Gaddam, S.K.Venkata, et al., New generation of bactericidal silver nanoparticles against different antibiotic resistant Escherichia coli strains. Appl Nanosci, 2015, 5(7): 847-855.

[14] V.S. Kotakadi, S.A. Gaddam, S.K. Venkata, et al., Biofabrication and spectral characterization of silver nanoparticles and their cytotoxic studies on human CD34 +ve stem cells. 3 Biotech, 2016, 6(2): 216.

[15] V.A. Litvin, B.F. Minaev, Spectroscopy study of silver nanoparticles fabrication using synthetic humic substances and their antimicrobial activity. Spectrochimica Acta Part A Molecular and Biomolecular Spectroscopy, 2013, 108: 115-122.

[16] K. Chaloupka, Y. Malam, and A.M. Seifalian, Nanosilver as a new generation of nanoproduct in biomedical applications. Trends Biotechnol, 2010, 28: 580-588.

[17] P. Singh, Y.J. Kim, and D.C. Yang. A strategic approach for rapid synthesis of gold and silver nanoparticles by Panax ginseng leaves. Artif. Cells Nanomed. Biotechnol., 2016, 44: 1949-1957.

[18] L. Xin, J. Wang, G. Fan, et al., Oxidative stress and mitochondrial injury-mediated cytotoxicity induced by silver nanoparticles in human A549 and HepG2 cells. Environ. Toxicol., 2015, 12: 1691-1699.

[19] D.R. Nogueira, C.M.B. Rolim, and A.A. Farooqi, Nanoparticle induced oxidative stress in cancer cells: adding new pieces to an incomplete jigsaw puzzle. Asian Pac. J. Cancer Prev., 2014, 15: 4739-4743.

[20] V. Castro Aceituno, S. Ahn, S.Y.Simu, et al., Silver nanoparticles from Dendropanax morbifera Léveille inhibit cell migration, induce apoptosis, and increase generation of reactive oxygen species in A549 lung cancer cells. In Vitro Cell Dev Biol Anim., 2016, 52: 1012-1019.

[21] A.K. Mittal, A. Kaler, and U.C. Banerjee, Free radical scavenging and antioxidant activity of silver nanoparticles synthesized from flower extract of Rhododendron dauricum. Nano BioMed Eng., 2006, 4: 118-124.

[22] E. Pick, D. Mizel, Rapid microassays for the measurement of superoxide and hydrogen peroxide production by macrophages in culture using an automatic enzyme immunoassay reader. J Immunol Methods, 1981, 46: 211 226.

[23] A. Sousa, I.C.F.R. Ferreira, L. Barros, et al., Effect of solvent and extraction temperatures on the antioxidant potential of traditional stoned table olives "alcaparras". Food Sci Technol-LWT., 2008, 41: 739-745.

[24] T. Mosmann, Rapid colorimetric assay for cellular growth and survival: application to proliferation and cytotoxicity assays. J Immunol Methods, 1983, 65: 55-63.

[25] Indian Drug Manufacturer's Association, Indian herbal pharmacopoeia revised new edition 2002. Indian Drug Manufacturer's Association, Mumbai. 2002: 429-438.

[26] A.S. Saroya, Herbalism phytochemistry and ethanopharmacology. Science Publishers, 2011: 357-361.

[27] S.N. Motamarri, M. Karthikeyan, M. Kannan, et al., Terminalia belerica. Roxb -- a phytopharmacological review. International Journal of Research in Pharmaceutical and Biomedical Sciences, 2012, 3: 96-99.

[28] U. Kreibig, M. Vollmer, Optical properties of metal clusters. Springer, 1995: 1-532.

[29] T.C. Prathna, N. Chandrasekaran, M. Ashok,et al., Biomimetic synthesis of silver nanoparticles by Citrus limon (lemon) aqueous extract and theoretical prediction of particle size. Colloids Surf B, 2011, 82: 152-159.
[30] J.J. Mock, M. Barbic, D.R. Smith, et al., Shape effects in plasmon resonance of individual colloidal silver nanoparticles. J. Chem. Phys., 2002, 116: 6755-6759.

[31] K. Vijayaraghavan, S.P. Kamala Nalini, N. Udaya Prakash, et al., One step green synthesis of silver nano/ microparticles using extracts of Trachyspermum ammi and Papaver somniferum. Colloids Surf. B, 2012, 94: 114117.

[32] P. Sivalingam, J.J. Antony, D. Siva, et al., Mangrove Streptomyces sp. BDUKAS10 as nanofactory for fabrication of bactericidal silver nanoparticles. Colloids Surf. B, 2012, 98: 12-17.

[33] A. Panacek, L. Kvítek, R. Prucek, et al., Silver colloid nanoparticles: synthesis, characterization, and their antibacterial activity. J Phys Chem B, 2006, 110: 1624816253.

[34] A.R. Shahverdi, S. Minaeian, H.R. Shahverdi, et al., Rapid synthesis of silver nanoparticles using culture supernatants of Enterobacteria: A novel biological approach. Process Biochem., 2007, 42: 919-923.

[35] R. Vijayalakshmi, R. Ravindhran, Comparative fingerprint and extraction yield of Diospyrus ferrea (willd.) Bakh. root with phenol compounds (gallic acid), as determined by UV-Vis and FT-IR spectroscopy. Asian Pac J Trop Biomed, 2012, 2: 1367.

[36] O.R. Sanchez, P. Balderas, N. Flores, et al., Gamma irradiation induced degradation of orange peels. Energies, 2012, 5: 3051-3063.

[37] P. Sandeep, C. Gunjan, P. Jayasinh, et al., Instant green synthesis of silver-based herbo-metallic colloidal nanosuspension in Terminalia bellirica fruit aqueous extract for catalytic and antibacterial applications. 3 Biotech, 2017, 7: 1-12.

[38] S.A. Gaddam, V.S. Kotakadi, Y. Subba Rao, et al., Efficient and robust biofabrication of silver nanoparticles by cassia alata leaf extract and their antimicrobial activity. J Nanostruct Chem, 2014, 4: 82.

[39] V.A. Litvin, R.L. Galagan, and B.F. Minaev, Kinetic and mechanism formation of silver nanoparticles coated by synthetic humic substances. Colloids \& Surfaces A: Physicochem. Eng. Aspects, 2012, 414: 234-243.

[40] A.K. Suresh, M.J. Doktycz, W. Wang, et al., Monodispersed biocompatible silver sulfide nanoparticles: facile extracellular biosynthesis using the $\gamma$-proteobacterium, Shewanella oneidensis. Acta Biomater, 2011, 7: 4253-4258.

[41] P. Rauwel, S. Kuunal, S. Ferdov, et al., A review on the green synthesis of silver nanoparticles and their morphologies studied via TEM. Adv Mater Sci Eng, 2015.

[42] S. Ghosh, S. Patil, M. Ahire et al., Synthesis of silver nanoparticles using Dioscorea bulbifera tuber extract and evaluation of its synergistic potential in combination with antimicrobial agents. Int J Nanomedicine, 2012, 7: 483496.

[43] C.G. Kumar, Y. Poornachandra, Biodirected synthesis of Miconazole-conjugated bacterial silver nanoparticles and their application as antifungal agents and drug delivery vehicles. Colloids Surf B Biointerfaces, 2015, 125: 110119.

[44] V.R. Netala, S. Bukke, L. Domdi, et al., Biogenesis of silver nanoparticles using leaf extract of Indigofera hirsuta L. and their potential biomedical applications (3-in-1 system). Artificial Cells, Nanomedicine and Biotechnology, 2018, 7: 1-11.

[45] B. Ajitha, Y.A. Reddy, and P.S. Reddy, Biosynthesis of silver nanoparticles using Momordica charantia leaf broth: Evaluation of their innate antimicrobial and catalytic activities. J Photochem Photobiol B Biol, 2015, 146: 1.

[46] P. Dauthal, M. Mukhopadhyay, Biosynthesis of palladium nanoparticles using Delonix regia leaf extract and its 
catalytic activity for nitro-aromatics hydrogenation. Ind Eng Chem Res, 2013, 52: 18131-18139.

[47] C.H. Ramamurthy, M. Padma, and I.D. Samadanam, The extra cellular synthesis of gold and silver nanoparticles and their free radical scavenging and antibacterial properties. Colloids Surf B Biointerfaces, 2013, 102: 808815.

[48] W. He, Y.T. Zhou, W.G. Wamer, et al., Mechanisms of the $\mathrm{pH}$ dependent generation of hydroxyl radicals and oxygen induced by Ag nanoparticles. Biomaterials, 2012, 33: 7547-7555.

[49] R. Mata, J.R. Nakkala, and S.R. Sadras, Biogenic silver nanoparticles from Abutilon indicum: their antioxidant, antibacterial and cytotoxic effects in vitro. Coll Surf B Biointerfaces,.2015, 128: 276-286.

[50] H.S.A. Al-Shmgani, W.H. Mohammed, G.M. Sulaiman, et al., Biosynthesis of silver nanoparticles from Catharanthus roseus leaf extract and assessing their antioxidant, antimicrobial, and wound-healing activities. Artificial Cells, Nanomedicine and Biotechnology, 2017, 45: 12341240.

[51] D.D. Rees, R.M. Palmer, and S. Moncada, Role of endothelium-derived nitric oxide in the regulation of blood pressure. Proc Natl Acad Sci U.S.A., 1989, 86: 3375-3378.

[52] G. Rodriguez-Gattorno, D. Diaz, L. Rendon, et al., Metallic nanoparticles from spontaneous reduction of silver(I) in DMSO. Interaction between nitric oxide and silver nanoparticles. J Phys Chem B, 2002, 106: 2482-
2487.

[53] S. Francis, S. Joseph, P.K. Ebey et al., Microwave assisted green synthesis of silver nanoparticles using leaf extract of elephantopus scaber and its environmental and biological applications. Artificial Cells, Nanomedicine, and Biotechnology, 2017: 795-804.

[54] A.K. Gade, P. Bonde, A.P. Ingle, et al., Exploitation of Aspergillus niger for synthesis of silver nanoparticles. $J$ Biobased Mater Bioenergy, 2008, 2(3): 243-247.

[55] J.R. Morones, J.L. Elechiguerra, A. Camacho, et al., The bactericidal effect of silver nanoparticles. Nanotechnology, 2005, 16: 2346-2353.

[56] S. Mukherjee, D. Chowdhury, R. Kotcherlakota, et al., Potential theranostics application of bio-synthesized silver nanoparticles (4-in-1 system). Theranostics, 2014, 4: 316335.

[57] R. Vivek, R. Thangam, K. Muthuchelian, et al., Green biosynthesis of silver nanoparticles from Annona squamosa leaf extract and its in vitro cytotoxic effect on MCF-7 cells. Process Biochem, 2012, 47: 2405-2410.

Copyright $(\subseteq$ Sucharitha Kumaram Venkata, Susmila Aparna Gaddam, Venkata Subbaiah Kotakadi, and Divi Venkata Ramana Sai Gopal. This is an open-access article distributed under the terms of the Creative Commons Attribution License, which permits unrestricted use, distribution, and reproduction in any medium, provided the original author and source are credited. 